\title{
Impact of Religiosity on Delirium Severity Among Critically III Shi'a Muslims: A Prospective Multi-Center Observational Study
}

\author{
Behrooz Farzanegan ${ }^{1}\left[\right.$. Takwa H.M. Elkhatib ${ }^{2}$. Alaa E. Elgazzar ${ }^{3}$. \\ Keivan G. Moghaddam ${ }^{4} \cdot$ Mohammad Torkaman $^{5} \cdot$ Mohammadreza Zarkesh $^{6}$. \\ Reza Goharani ${ }^{7}$. Farshid R. Bashar ${ }^{8}$. Mohammadreza Hajiesmaeili ${ }^{7}$. \\ Seyedpouzhia Shojaei ${ }^{7}$. Seyed J. Madani ${ }^{9}$. Amir Vahedian-Azimi ${ }^{10}$. \\ Sevak Hatamian $^{11}$. Seyed M.M. Mosavinasab ${ }^{12}$. Masoum Khoshfetrat ${ }^{13}$. \\ Ali K. Khatir ${ }^{14}$. Andrew C. Miller ${ }^{15}$. for the MORZAK Collaborative
}

Published online: 21 August 2019

(c) Springer Science+Business Media, LLC, part of Springer Nature 2019

\begin{abstract}
This study assesses the impact of religiosity on delirium severity and patient outcomes among Shi' a Muslim intensive care unit (ICU) patients. We conducted a prospective observational cohort study in 21 ICUs from 6 Iranian academic medical centers. Delirium was assessed using the Confusion Assessment Method for the ICU (CAM-ICU) tool. Eligible patients were intubated, receiving mechanical ventilation (MV) for $\geq 48$ h. Illness severity was assessed using Acute Physiology and Chronic Health Evaluation II (APACHE II) scores. A total of 4200 patients were enrolled. Patient religiosity was categorized as more $(40.6 \%)$, moderate $(42.3 \%)$, or less $(17.1 \%)$ based on responses to patient and surrogate questionnaires. The findings suggest that lower pre-illness religiosity may be associated with greater delirium severity, MV duration, and ICU and hospital LOS. The lower mortality in the less religiosity group may be related in part to a greater proportion of female patients, but it remains unclear whether and to what extent greater religiosity impacted treatment decisions by patients and families. Further investigation is needed to validate and clarify the mechanism of the mortality findings.
\end{abstract}

Keywords Delirium · Intensive care unit · Critical care $\cdot$ Religion $\cdot$ Religiosity

Andrew C. Miller

Taqwa1@gmail.com; MillerAndr17@ECU.edu

Extended author information available on the last page of the article 


\section{Introduction}

Delirium is a transient global disorder of cognition associated with increased morbidity and mortality (Pisani et al. 2010). Early recognition, treatment, and symptoms resolution are correlated with favorable outcomes (Vahedian-Azimi et al. 2015). The mechanism remains unclear, and no diagnostic test is available. In intensive care unit (ICU) patients, the prevalence may reach as high as $80 \%$ (Kalabalik et al. 2014), with a daily probability of transitioning into delirium as high as $14 \%$ (Schreiber et al. 2014). ICU delirium may also be a predictor of increased mortality and prolonged ICU length of stay (LOS) (Yamaguchi et al. 2014), prolonged hospital LOS (Al-Qadheeb et al. 2016; Mehta et al. 2015; Trogrlic et al. 2015), increased complications, hospital costs (Gleason et al. 2015), long-term disability (Marcantonio et al. 2005), long-term cognitive impairment (Pandharipande et al. 2013; Sukantarat et al. 2005), and decreased odds of discharge home (Devlin et al. 2012; Shehabi et al. 2010; Tsuruta et al. 2010).

The American Psychiatric Association's Diagnostic and Statistical Manual, 5th edition (DSM-V) defines delirium by: disturbances of (1) attention, (2) cognition, (3) that develops over a short period, (4) that is a change from baseline, (5) that fluctuates, (5) not otherwise explained by another neurocognitive disorder, (6) with evidence suggesting a potential cause in the history, physical examination, or laboratory findings (American Psychiatry Association 2013).

Despite the high incidence, delirium remains understudied. Furthermore, it remains unclear what role pre-illness beliefs and practices, including religiosity and spirituality $(\mathrm{R} / \mathrm{S})$, may play in delirium development or recovery.

The WHO definition of health comprises physical, psychological, and spiritual factors as well as social well-being (World Health Organization 1998). The potential for both positive and negative effects of R/S on health, combined with the high levels of engagement, suggests that this area is ripe for research as evidenced by the marked increase in R/S health research over the past decade (Bagiella et al. 2005; Ellison and Levin 1998; Park et al. 2016; Pereira et al. 2010; Powell et al. 2003). For many patients who face life-threatening illness, R/S and associated resources may be particularly relevant and important determinant factors of their quality of life (QoL) (Atef-Vahid et al. 2011; Balboni et al. 2013; Bonelli et al. 2012; Bulow et al. 2012; Darviri et al. 2016; Ironson et al. 2016). Religious participation is related to better outcomes for persons who are recovering from physical and mental illness and is correlated with improved mental and physical health and longevity (Alves et al. 2010).

Research has consistently linked indices of religious coping to measures of health and well-being, a major source of support and hope, among diverse groups recovering from physical and mental illness or facing critical life events (Alves et al. 2010; Marcantonio et al. 2005; Mardiyono et al. 2011; Saisunantararom et al. 2015; Shehabi et al. 2010). Hence, these are factors of vital importance to many ICU and their families (Shinall et al. 2014; Wall et al. 2007). Although some literature assessing the relationship between R/S and ICU outcomes does exist, there is a paucity of data regarding the interplay of $\mathrm{R} / \mathrm{S}$ and delirium. The 
objective of this study was to investigate whether pre-admission religiosity correlated with delirium severity, or patient outcomes including survival, illness severity, and hospital and ICU LOS.

\section{Methods}

\section{Study Design and Setting}

We conducted a prospective observational cohort study in 21 ICUs (10 mixed, 5 surgical, 6 medical) from 6 academic medical centers across 4 Iranian provinces from October 1, 2007, to May 30, 2015. All 7750 patients presenting during this period were screened for enrollment. All study parts were reviewed according to the Strengthening the Reporting of Observational Studies in Epidemiology "STROBE" (von Elm et al. 2007).

\section{Participants}

The inclusion criteria were: (1) age $\geq 18$ years, (2) endotracheally intubated and on mechanical ventilation (MV) for $\geq 48 \mathrm{~h}$, (3) full-code status, and (4) informed consent obtained from the patient, legal guardian, or healthcare surrogate.

Patients were excluded for: (1) no consent, (2) death while on ventilator, (3) permanent ventilator dependence, (4) tracheostomy placement for long-term weaning, (5) discrepancy between patient and his/her surrogate opinion about the patient's religious degree, (6) copious excessive/secretions precluding wean, and (7) incomplete data.

\section{Delirium}

Delirium was assessed during each shift (three times daily) by the bedside nurse and researcher (kappa agreement coefficient 0.801-0.902), using the Confusion Assessment Method for the ICU (CAM-ICU) screening tool. The CAM-ICU allows the clinician to screen for the presence (not severity) of delirium in critically ill patients, including those on MV (sensitivity 75.5\%, specificity 95.8\%) (Ely et al. 2001a, b; Neto et al. 2012). It makes use of nonverbal assessments to evaluate important features of delirium and is one of the most specific bedside tools to diagnose delirium in critically ill patients. Delirium severity was determined using the delirium rating scale-revised-98 (DRS-R-98) (Trzepacz et al. 2001). Investigators also recorded the number of shifts during which patients were noted to have a delirious episode. Delirium was further subcategorized into binary low/high groups and stratified into low, moderate, and high for additional analysis. Optimal thresholds were selected by receiver operating curve (ROC) analysis of a database of 16,000 ICU patients. To achieve a sensitivity of $95 \%$ and a specificity of $95 \%$, binary and ordinal categorizations were observed to have the best ROC characteristics. Thresholds selection was discussed in a qualitative panel of 31 members including two psychiatrists, three 
psychologists, five intensivists, three neurologists, three internists, five anesthesiologists, and ten ICU nurses. Consensus agreement was achieved based on the available data.

\section{Religiosity Grouping}

Upon screening positive for delirium, the patient's designated surrogate was asked about the patient's baseline level of religiosity. When available, patients were asked the same questions upon their clinical improvement. A kappa agreement coefficient was determined between patients and their surrogates $(0.923 ; p<0.0001)$. The components of religiosity determination included: (i) 5 obligatory daily prayers (Salaat) or 17 rakats per day; (ii) Nafilah prayers (34 rakats); (iii) fasting (Sawm) during Ramadan and other recommended days; (iv) reading one or more pages of Qur'ān daily; (v) performance of additional optional acts of faith including following the example (Sunnah) of the prophet Muhammad, making additional supplications $(D u a)$, and reading sermons of notable Imams. The high religiosity category was defined as always fulfilling criteria (i) through (v). The moderate religiosity group was defined as always meeting criteria (i) and (iii), and sometimes (ii), (iv), and (v). The less religiosity group was defined as meeting not more than criteria (i) and (iii). Assignment of categorization was done using the 3-round Delphi technique.

\section{Ethical Considerations}

The study was approved by the investigational review board at Baqiyatallah University of Medical Sciences (IR.BMSU.REC.1394.451), whose approval was accepted by each enrolling site. Surrogate consent from the patient's legal guardian or designated health proxy was permitted in cases where the patient did not have decision-making capacity. All patients that survived and regained their faculties were informed of the project.

\section{Sample Size}

The sample size was calculated for the occurrence of ICU delirium. By considering a delirium prevalence of $0.5,95 \%$ confidence interval level, $80 \%$ power, and absolute error $10 \%$, the necessary sample size was calculated to be 4200 patients. Sample size calculation was performed using G-Power 3.1.2 software (available at http:// www.gpower.hhu.de/) (Faul et al. 2009).

\section{Data Collection}

Baseline demographics (age, sex, marital status, smoking status), hospital data (diagnosis, ICU LOS, hospital LOS, MV duration, comorbidities, sedation, Acute Physiology and Chronic Health Evaluation (APACHE) II score, and mortality), delirium presence and severity, and religiosity level were collected for each patient. The primary outcome was to determine whether religiosity correlated with delirium 
severity. Secondary outcomes were to determine whether religiosity correlated with patient outcomes including survival, illness severity, and hospital and ICU length of stay.

\section{Availability of Data and Materials}

This study was part of a much larger project, and not all data are published in this manuscript. De-identified individual subject data may be available from the corresponding author on reasonable request for researchers who meet the criteria for access to confidential data.

\section{Statistical Analysis}

Continuous variables were expressed as the mean $\pm \mathrm{SD}$ and median (interquartile range), and the categorical variables were expressed as a number (percentage). Continuous variables were checked for normality by using Shapiro-Wilk test. Independent samples Student's $t$ test was used to compare between two groups of normally distributed variables. One-way ANOVA test was used to compare between more than two groups of normally distributed variables. Percent of categorical variables were compared using Pearson's Chi-square $\left(\chi^{2}\right)$ test or Fisher's exact test when was appropriate. Trend of change in distribution of relative frequencies between ordinal data was compared using $\chi^{2}$ test for trend. To determine predictors for high delirium, univariate logistic regression was done. Backward multivariate logistic regression analysis model was done using any predictor with $\mathrm{p}$ value $<0.2$ in univariate analysis. All tests were two-sided. $p$ Value $<0.05$ was considered significant. Lastly, a multivariate analysis was performed to identify variables associated with mortality. All statistics were performed using IBM ${ }^{\circledR}$ SPSS ${ }^{\circledR} 22.0$ (IBM Corp., Armonk, NY) and MedCalc ${ }^{\circledR}$ (MedCalc Software bvba 13, Ostend, Belgium).

\section{Results}

A total of 7750 potential patients were approached to participate. A total of 199 declined to participate. A total of 4200 were included in the final analysis, and 3351 patients were excluded for reasons including: patient death before weaning $(n=616)$; permanent ventilator dependence $(n=167)$; tracheostomy placement for long-term weaning $(n=489)$; copious secretions precluding wean $(n=1494)$; discrepancy between patient and surrogate precluding classification $(\mathrm{n}=475)$; insufficient data gathered $(n=110$; Fig. 1$)$. Demographic and clinical features are summarized in Table 1. All patients were Shi'a Muslims. The mean age was $67 \pm 11.5$ years with a female predominance $(58 \%)$. Patients were categorized by religiosity into high $(40.6 \%)$, moderate $(42.3 \%)$, or less $(17.1 \%)$ religiosity groups. Overall, patients were admitted for sepsis (29.9\%), acute respiratory distress syndrome (ARDS; 19.6\%), trauma $(17.5 \%)$, abdominal surgery $(15.9 \%)$, pneumonia $(10.2 \%)$, COPD $(8.6 \%)$, pulmonary edema $(5.8 \%)$, and 


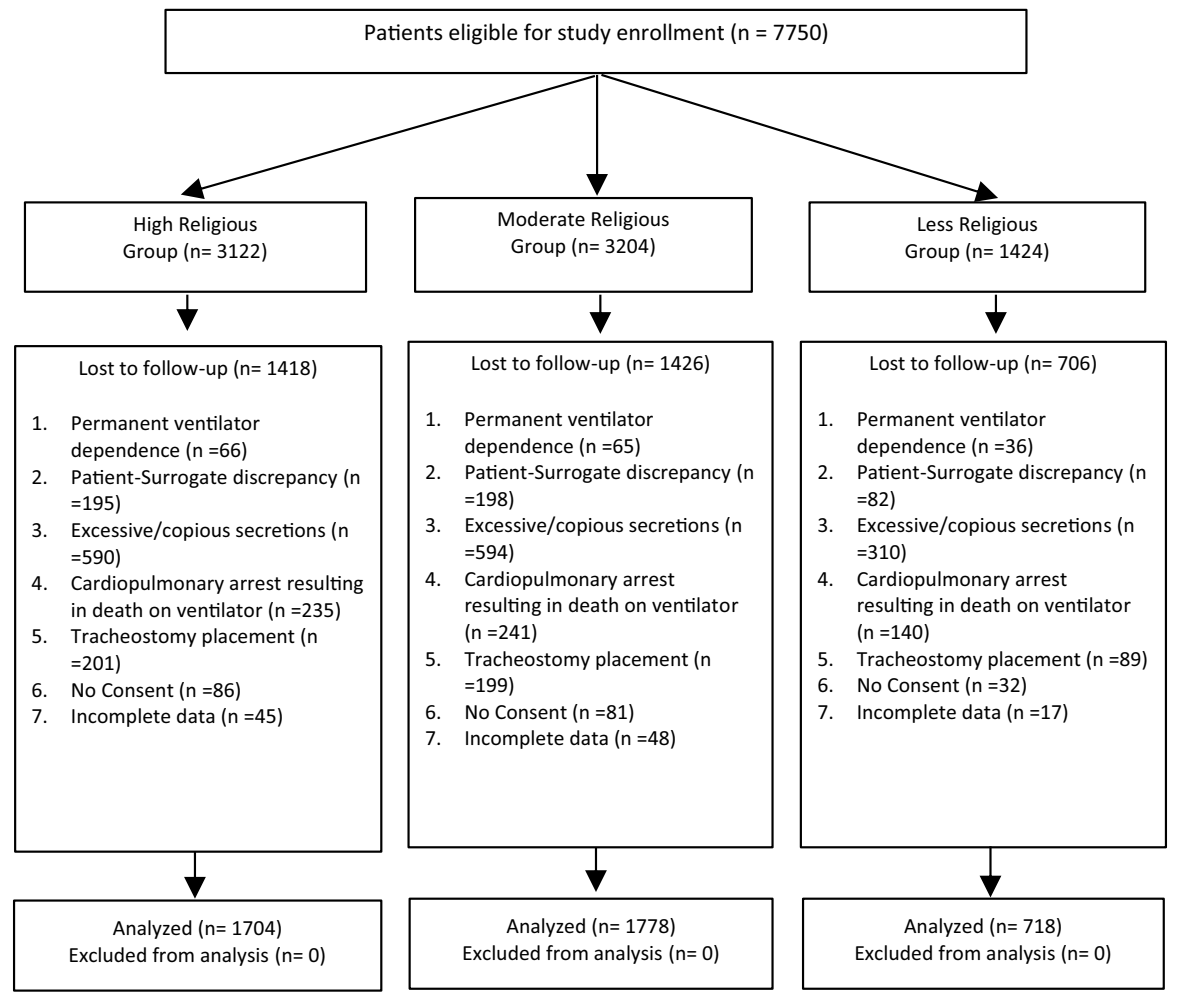

Fig. 1 CONSORT 2010 flow diagram

miscellaneous other (1.3\%). Admission diagnoses were similar between groups as shown in Table 2. The overall mean delirium duration was $23.32 \pm 7.88$ days. The mean hospital length of stay (LOS) was 19.6 \pm 10.9 days (range 8-98), with a mean ICU LOS of $16.8 \pm 10.9$ days (range 9-93). The mean intubation duration was $326.5 \pm 110.3 \mathrm{~h}$ (range 140-602). The mean APACHE II score was $15 \pm 2.4$ (range 11-22), and the mortality rate was $27.8 \%$.

Increasing age directly correlated with both degree of religiosity (Table 3), delirium severity (Table 4), and greater in-hospital mortality. Although statistically significant, the (mean difference \pm standard deviation) differences in age relative to sedation dose were not clinically significant: high versus moderate $(1.48 \pm 0.46$ years; $p=0.003)$, high versus low $(2.40 \pm 0.53 ; p<0.001)$, moderate versus low $(0.92 \pm 0.43$ years; $p=0.08)$.

Religiosity, however, correlated inversely with delirium severity (Table 5). A description of comorbidities is provided in Table 6. Patients differed in comorbidities when stratified by religiosity $(p<0.001)$, and $\chi^{2}$ testing revealed significant relationship between comorbidities and delirium duration $(p=0.042)$. Moreover, increasing comorbidities correlated significantly with patient mortality (Table 7). 
Table 1 Patient demographics, illness severity, and delirium severity

\begin{tabular}{|c|c|c|c|c|c|}
\hline \multirow[t]{2}{*}{ Characteristics } & \multicolumn{2}{|c|}{$\begin{array}{l}\text { All studied patients } \\
(N=4200)\end{array}$} & \multirow[t]{2}{*}{ Characteristics } & \multicolumn{2}{|c|}{$\begin{array}{l}\text { All studied patients } \\
(N=4200)\end{array}$} \\
\hline & Number & $\%$ & & Number & $\%$ \\
\hline Age (year) & & & Disease & & \\
\hline Mean \pm SD & $67.25 \pm 11.57$ & & COPD & 363 & 8.6 \\
\hline Median (range) & $65(50-93)$ & & ARDS & 830 & 19.6 \\
\hline Sex & & & Sepsis & 876 & 20.9 \\
\hline Male & 1761 & 41.9 & Multiple trauma & 737 & 17.5 \\
\hline Female & 2439 & 58.1 & Abdominal surgery & 668 & 15.9 \\
\hline Marital status & & & Pneumonia & 430 & 10.2 \\
\hline Unmarried & 489 & 11.6 & Pulmonary edema & 242 & 5.8 \\
\hline Married & 3360 & 80 & Miscellaneous & 54 & 1.3 \\
\hline Divorced & 351 & 8.4 & & & \\
\hline Smoking & & & APACHE II & & \\
\hline Current and ex-smoker & 2734 & 65.1 & Mean \pm SD & $15.60 \pm 2.41$ & \\
\hline \multirow[t]{4}{*}{ Never smoking } & 1466 & 34.9 & Median (range) & $15(11-22)$ & \\
\hline & & & Survival & & \\
\hline & & & Death & 1169 & 27.8 \\
\hline & & & Alive & 3031 & 72.2 \\
\hline Religious status & & & Shifts with delirious episode & & \\
\hline More religious & 1704 & 40.6 & Mean \pm SD & $23.32 \pm 7.88$ & \\
\hline Medium religious & 1778 & 42.3 & Median (range) & $24(10-43)$ & \\
\hline Less religious & 718 & 17.1 & Delirium* (binary) & & \\
\hline $\begin{array}{l}\text { Hospital length of stay } \\
\text { (days) }\end{array}$ & & & Less delirium (10-23) & 2030 & 48.3 \\
\hline Mean \pm SD & $19.64 \pm 10.93$ & & High delirium (24-43) & 2170 & 51.7 \\
\hline Median (range) & $17(8-98)$ & & Delirium* (ordinal) & & \\
\hline ICU length of stay (days) & & & Less delirium (10-20) & 1403 & 33.4 \\
\hline Mean \pm SD & $16.77 \pm 10.89$ & & Moderate delirium (21-28) & 1364 & 32.5 \\
\hline Median (range) & $13(9-93)$ & & High delirium (29-43) & 1433 & 34.1 \\
\hline MV duration (days) & & & Physical restraints & & \\
\hline Mean \pm SD & $326.49 \pm 110.33$ & & Yes & 1763 & 42 \\
\hline Median (range) & $336(140-602)$ & & No & 2437 & 58 \\
\hline Sedation $^{\dagger}$ & & & Acute nursing care & & \\
\hline High dose & 891 & 21.2 & High & 854 & 20.3 \\
\hline Moderate & 2254 & 53.7 & Moderate & 2098 & 50 \\
\hline Low dose & 1055 & 25.1 & Low & 1248 & 29.7 \\
\hline
\end{tabular}

Continuous variables were expressed as the mean \pm SD and median (range); categorical variables were expressed as a number (percentage)

*Score according to the CAM-ICU scale

$\dagger$ Sedation levels determined in accordance with published recommendations (Miller et al. 2014; Nagaraj et al. 2016; Nagaraj et al. 2017)

$\ddagger$ Determined based on number of nursing hours needed per shift: high ( $\geq 8 \mathrm{~h}$ ), moderate (4-8 h), low $(<4 \mathrm{~h})$ 
Table 2 Association between study variables, delirium, and degree of religiosity (univariate analysis)

\begin{tabular}{llll}
\hline Study variables & $\begin{array}{l}\text { More religious } \\
(n=1704)\end{array}$ & $\begin{array}{l}\text { Moderate } \\
\text { religious } \\
(n=1778)\end{array}$ & Less religious $(n=718) \quad p$ Value \\
& & \\
\end{tabular}

\begin{tabular}{|c|c|c|c|c|}
\hline \multicolumn{5}{|l|}{ Age (years) } \\
\hline Mean \pm SD & $66.82 \pm 9.23$ & $63.84 \pm 11.75$ & $76.71 \pm 10.98$ & \multirow[t]{2}{*}{$<0.001 *$} \\
\hline Median (range) & $65(51-92)$ & $60(50-93)$ & $78(51-93)$ & \\
\hline Sex (female) & $909(53.3 \%)$ & $1060(59.6 \%)$ & $470(65.5 \%)$ & $<0.001^{\dagger}$ \\
\hline \multicolumn{5}{|l|}{ Marital status } \\
\hline Unmarried & $243(14.3 \%)$ & $174(9.8 \%)$ & $72(10 \%)$ & \multirow[t]{3}{*}{$<0.001^{\dagger}$} \\
\hline Married & $1389(81.5 \%)$ & $1427(80.3 \%)$ & $544(75.8 \%)$ & \\
\hline Divorced & $72(4.2 \%)$ & $177(10 \%)$ & $102(14.2 \%)$ & \\
\hline \multicolumn{5}{|l|}{ Smoking status } \\
\hline Current and former & $1185(69.5 \%)$ & $1061(59.7 \%)$ & $488(68 \%)$ & \multirow[t]{2}{*}{$<0.001^{\dagger}$} \\
\hline Never & $519(30.5 \%)$ & $717(40.3 \%)$ & $230(32 \%)$ & \\
\hline \multicolumn{5}{|l|}{ Hospital LOS (days) } \\
\hline Mean \pm SD & $18.95 \pm 7.74$ & $20.04 \pm 13.21$ & $20.28 \pm 11.10$ & \multirow[t]{2}{*}{$0.003^{*}$} \\
\hline Median (range) & $17(8-56)$ & $16(8-98)$ & $17(9-85)$ & \\
\hline \multicolumn{5}{|l|}{ ICU LOS (days) } \\
\hline Mean \pm SD & $16.04 \pm 7.74$ & $17.21 \pm 13.13$ & $17.41 \pm 11.10$ & \multirow[t]{2}{*}{$0.001 *$} \\
\hline Median (range) & $14(9-53)$ & $13(9-93)$ & $13(9-78)$ & \\
\hline \multicolumn{5}{|l|}{ MV duration (hours) } \\
\hline Mean \pm SD & $220.80 \pm 67.44$ & $378.32 \pm 66.94$ & $448.95 \pm 33.98$ & \multirow[t]{2}{*}{$<0.001^{*}$} \\
\hline Median (range) & $196(140-490)$ & 364 (280-602) & $448(378-560)$ & \\
\hline \multicolumn{5}{|l|}{ Illness } \\
\hline COPD & $139(8.2 \%)$ & $162(9.1 \%)$ & $60(8.6 \%)$ & \multirow[t]{8}{*}{$0.001^{\dagger}$} \\
\hline Pneumonia & $175(10.3 \%)$ & $179(10.1 \%)$ & $76(10.6 \%)$ & \\
\hline Sepsis & $355(20.8 \%)$ & $372(20.9 \%)$ & $149(20.8 \%)$ & \\
\hline ARDS & $342(20.1 \%)$ & $350(19.7 \%)$ & $138(19.2 \%)$ & \\
\hline $\begin{array}{l}\text { Pulmonary edema/ } \\
\text { CHF }\end{array}$ & $98(5.8 \%)$ & $101(5.7 \%)$ & $43(6 \%)$ & \\
\hline Trauma & $301(17.7 \%)$ & $311(17.5 \%)$ & $125(17.4 \%)$ & \\
\hline Abdominal surgery & $273(16 \%)$ & $281(15.8 \%)$ & $114(15.9 \%)$ & \\
\hline Other & $21(1.2 \%)$ & $22(1.2 \%)$ & $11(1.5 \%)$ & \\
\hline \multicolumn{5}{|l|}{ APACHE II } \\
\hline Mean \pm SD & $15.64 \pm 2.45$ & $15.61 \pm 2.42$ & $15.45 \pm 2.30$ & \multirow[t]{2}{*}{$0.194 *$} \\
\hline Median (range) & $15(11-22)$ & $15(11-22)$ & $15(11-22)$ & \\
\hline \multicolumn{5}{|l|}{ Physical restraints } \\
\hline Yes & $642(37.7 \%)$ & $777(43.7 \%)$ & $344(47.9 \%)$ & \multirow[t]{2}{*}{$0.001^{\dagger}$} \\
\hline No & $1062(62.3 \%)$ & $1001(56.3 \%)$ & $374(52.1 \%)$ & \\
\hline \multicolumn{5}{|l|}{ Sedation dose $\mathrm{e}^{\frac{\dot{t}}{+}}$} \\
\hline High & $286(16.8 \%)$ & $396(22.3 \%)$ & $209(29.1 \%)$ & \multirow[t]{3}{*}{$<0.001^{\dagger}$} \\
\hline Moderate & $972(57 \%)$ & $915(51.5 \%)$ & $367(51.1)$ & \\
\hline Low & $446(26.2 \%)$ & $467(26.3 \%)$ & $142(19.8)$ & \\
\hline
\end{tabular}


Table 2 (continued)

\begin{tabular}{lllll}
\hline Study variables & $\begin{array}{l}\text { More religious } \\
(n=1704)\end{array}$ & $\begin{array}{l}\text { Moderate } \\
\text { religious } \\
(n=1778)\end{array}$ & Less religious $(n=718)$ & $p$ Value \\
\hline Acute nursing care ${ }^{* *}$ & $434(25.5 \%)$ & $336(18.9 \%)$ & $84(11.7 \%)$ & $<0.001^{\dagger}$ \\
High & $876(51.4)$ & $859(48.3 \%)$ & $363(50.6 \%)$ & $<0.001^{*}$ \\
Moderate & $394(23.1 \%)$ & $583(32.8 \%)$ & $271(37.7 \%)$ & \\
Low & $15.77 \pm 4.81$ & $27.02 \pm 4.78$ & $32.06 \pm 2.42$ & $<0.001^{\dagger}$ \\
Shifts with delirious episode & $26(20-43)$ & $32(27-40)$ & \\
Mean \pm SD & $14(10-35)$ & $1260(70.9 \%)$ & $718(100 \%)$ & \\
Median (range) & $192(11.3 \%)$ & $518(29.1 \%)$ & 0 & $<0.001^{\dagger}$ \\
Delirium (binary) $\dagger \dagger$ & $1512(88.7 \%)$ & $721(40.6 \%)$ & $694(96.7 \%)$ & \\
High & $18(1.1 \%)$ & $1021(57.4 \%)$ & $34(3.3 \%)$ & \\
Less & $319(18.7 \%)$ & $36(2 \%)$ & 0 & $0.027^{\dagger}$ \\
Delirium (ordinal) $\dagger \dagger$ & $1367(80.2 \%)$ & $503(28.3 \%)$ & $171(23.8 \%)$ & \\
High & $495(29 \%)$ & &
\end{tabular}

APACHE Acute Physiology and Chronic Health Evaluation

Continuous variables were expressed as the mean \pm SD and median (range); categorical variables were expressed as number (percentage); $p<0.05$ is significant

*One-way ANOVA test

$†$ Chi-square test

$¥$ Sedation levels determined in accordance with published recommendations (Miller et. al. 2015; Nagaraj et al. 2016, 2017)

**Determined based on number of nursing hours needed per 8-h shift: high ( $\geq 8 \mathrm{~h})$, moderate $(4-8 \mathrm{~h})$, low $(<4 \mathrm{~h})$

$\dagger \dagger$ Score according to the CAM-ICU scale

Table 3 Tukey highly significant difference comparison tests for age (dependent variable) and degree of religiosity: high, moderate, or less

\begin{tabular}{|c|c|c|c|c|c|}
\hline \multirow[t]{2}{*}{ Tukey test } & \multirow[t]{2}{*}{ Mean difference (SE) } & \multicolumn{2}{|c|}{$95 \%$ confidence interval } & \multirow[t]{2}{*}{$p$ Value } & \multirow[t]{2}{*}{ Inference } \\
\hline & & Lower bound & $\overline{\text { Upper bound }}$ & & \\
\hline High versus moderate & $2.98(0.36)$ & 2.13 & 3.82 & $<0.001$ & Significant \\
\hline High versus less & $-9.89(0.47)$ & -11.0 & -8.78 & $<0.001$ & Significant \\
\hline Moderate versus high & $-2.98(0.36)$ & -3.82 & -2.13 & $<0.001$ & Significant \\
\hline Moderate versus less & $-12.86(0.47)$ & -13.97 & -11.76 & $<0.001$ & Significant \\
\hline Less versus high & $9.89(0.47)$ & 8.78 & 11.0 & $<0.001$ & Significant \\
\hline Less versus moderate & $12.86(0.47)$ & 11.76 & 13.97 & $<0.001$ & Significant \\
\hline
\end{tabular}


Table 4 Tukey highly significant difference comparison tests for age (dependent variable) and degree of delirium: high (29-43), moderate (21-28), less (10-20)

\begin{tabular}{lcccrcr}
\hline Tukey test & Mean difference (SE) & \multicolumn{2}{l}{$95 \%$ confidence interval } & & \multirow{2}{*}{$p$ Value } & Inference \\
\cline { 3 - 4 } & & \multicolumn{2}{c}{ Lower bound } & Upper bound & & \\
\hline Less versus moderate & $-5.22(0.43)$ & -6.23 & -4.20 & $<0.001$ & Significant \\
Less versus high & $-3.78(0.43)$ & -4.78 & -2.78 & $<0.001$ & Significant \\
Moderate versus less & $5.21(0.43)$ & 4.20 & 6.23 & $<0.001$ & Significant \\
Moderate versus high & $1.44(0.43)$ & 0.43 & 2.45 & 0.002 & Significant \\
High versus less & $3.78(0.43)$ & 2.78 & 4.78 & $<0.001$ & Significant \\
High versus moderate & $-1.44(0.43)$ & -2.45 & -0.43 & & 0.002 & Significant \\
\hline
\end{tabular}

Table 5 Relationship between religiosity degree and delirium severity (binary categorization)

\begin{tabular}{lcccc}
\hline Religiosity & $\begin{array}{l}\text { Delirium (binary categoriza- } \\
\text { tion) }\end{array}$ & Total & $p$ Value \\
\cline { 2 - 3 } & $\begin{array}{l}\text { Less delirium } \\
(10-23)\end{array}$ & $\begin{array}{l}\text { High delirium } \\
{[24-43]}\end{array}$ & & \\
\hline Greater & 1512 & 192 & 1704 & $<0.001^{\text {a }}$ \\
Moderate & 518 & 1260 & 1778 & \\
Less & 0 & 718 & 718 & \\
Total & 2030 & 2170 & 4200 & \\
\hline
\end{tabular}

${ }^{\text {a }}$ Pearson $\chi^{2}$

In a multivariate analysis, variables significantly associated with mortality included: age $(p=0.003)$, sex $(p<0.001)$, comorbidities $(p<0.001)$, APACHE II score $(p=0.015)$, ICU LOS $(p<0.001)$, and hospital LOS $(p<0.001)$. Sedation level did not correlate with mortality (Table 8 ).

The delirium score was transformed in a binary scoring factor with less delirium indicating a delirium rating score of 10-23, and high delirium by a score of 24-43. A total of $51.7 \%(N=2170)$ of patients scored as high delirium. Upon performing binary logistic regression with degree of religiosity as a fixed variable, delirium (binary) was not a predictor of death in any group (Table 9). However, with binary logistic regression making the delirium a fixed variable, degree of religiosity was found to be a predictor of death in the high religiosity group (Table $10 ; p=0.003$ ).

Comparison of various parameters between the three degree of religiosity groups with delirium is shown in Table 2. In comparison with the other two groups, the less religiosity group had significantly higher delirium scores $(p<0.001)$ and more shifts with delirious episodes $(p<0.001)$. The increased incidence of severe delirium in the less religiosity group correlated with a concomitant increase in high dose sedation and physical restraint use. Univariate analysis showed that the less religious group had a significantly longer hospital LOS $(p=0.003)$, ICU LOS $(p=0.001)$, and duration of MV $(p<0.001)$, but lower in-hospital mortality $(23.8 \%$ vs. $29 \%$, $p=0.027$ ). 


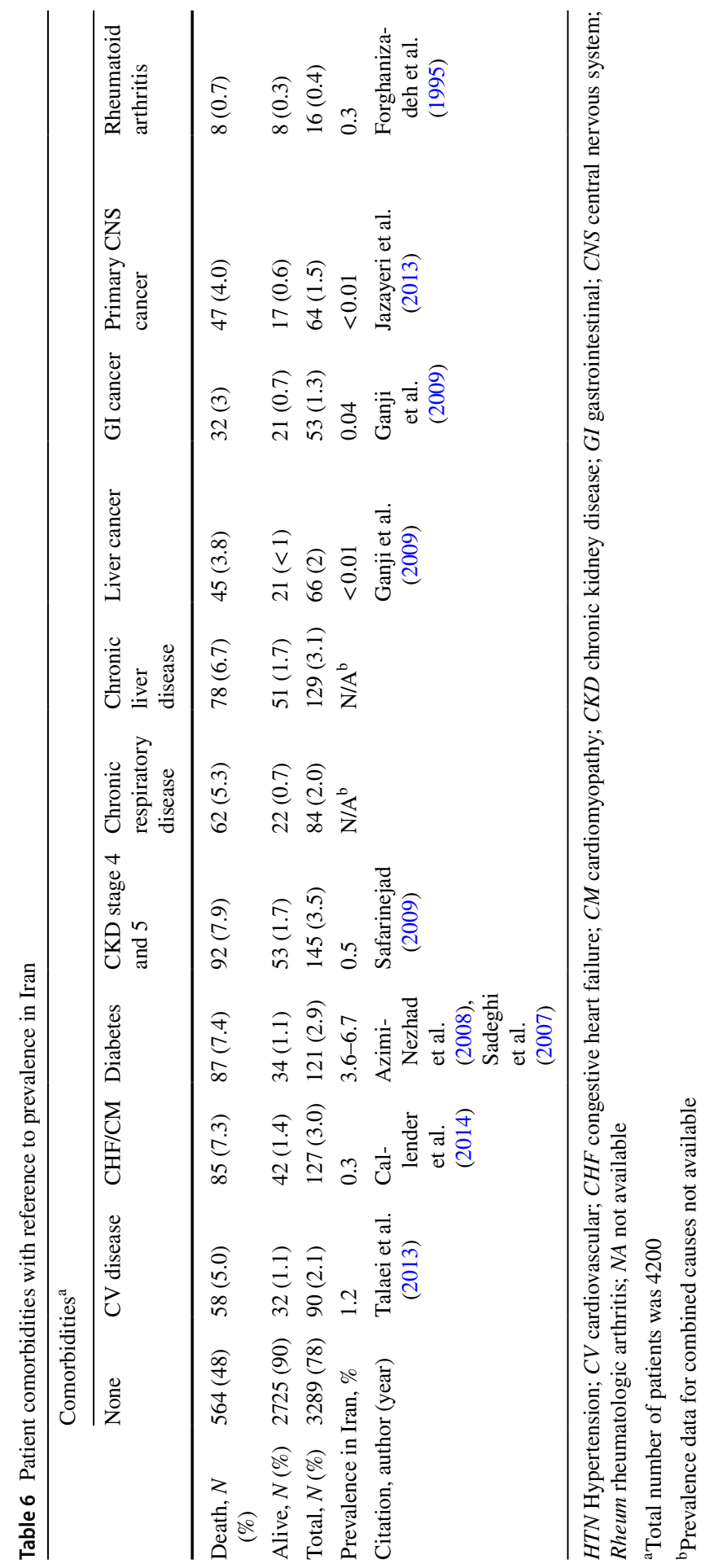


Table 7 Relationship between the presence of comorbidities and patient mortality

\begin{tabular}{|c|c|c|c|c|}
\hline \multirow[b]{2}{*}{ Mortality } & \multicolumn{2}{|c|}{ Comorbidities } & \multirow[t]{2}{*}{ Total, $n(\%)$} & \multirow[t]{2}{*}{$p$ Value } \\
\hline & Yes & No & & \\
\hline Dead & 605 & 564 & 1169 (27.8) & $<0.001^{\mathrm{a}}$ \\
\hline Alive & 306 & 2725 & $3031(72.2)$ & \\
\hline Total & 911 & 3289 & $4200(100)$ & \\
\hline
\end{tabular}

${ }^{\mathrm{a}}$ Pearson $\chi^{2}$

Table 8 Relationship between sedation dose and patient mortality

\begin{tabular}{llcccc}
\hline Mortality & High dose $N(\%)$ & Moderate dose $N(\%)$ & Low dose $N(\%)$ & Total, $n(\%)$ & $p$ Value \\
\hline Dead & $256(28.7 \%)$ & $607(26.9 \%)$ & $306(29 \%)$ & $1169(27.8 \%)$ & $0.369^{a}$ \\
Alive & $635(71.3 \%)$ & $1647(73.1 \%)$ & $749(71 \%)$ & $3031(72.2 \%)$ & \\
Total & $891(100 \%)$ & $2254(100 \%)$ & $1055(100 \%)$ & $4200(100 \%)$ & \\
\hline
\end{tabular}

${ }^{\text {a Pearson }} \chi^{2}$

Table 9 Delirium (binary) as a mortality predictor, with religious status as fixed variable

\begin{tabular}{|c|c|c|c|c|}
\hline \multirow[t]{3}{*}{ Religious status/Delirium (binary) } & \multirow{3}{*}{$\begin{array}{l}\text { All stud- } \\
\text { ied patients } \\
(N=4200) \\
\text { No. }(\%)\end{array}$} & \multicolumn{2}{|l|}{ Outcome } & \multirow[t]{3}{*}{$p$ Value } \\
\hline & & Death $(N=1169)$ & Alive $(N=3031)$ & \\
\hline & & No. $(\%)$ & No. $(\%)$ & \\
\hline More religious group & $1704(40.6 \%)$ & $495(29 \%)$ & $1209(71 \%)$ & \\
\hline Less delirium & $1512(88.7 \%)$ & $432(28.6 \%)$ & $1080(71.4 \%)$ & $0.223^{\mathrm{a}}$ \\
\hline High delirium & $192(11.3 \%)$ & $63(32.8 \%)$ & $129(67.2 \%)$ & \\
\hline Moderate religious group & $1778(42.3 \%)$ & $503(28.3 \%)$ & $1275(71.7 \%)$ & \\
\hline Less delirium & $518(29.1 \%)$ & $136(26.3 \%)$ & $382(73.7 \%)$ & $0.222^{\mathrm{a}}$ \\
\hline High delirium & $1260(70.9 \%)$ & $367(29.1 \%)$ & $893(70.9 \%)$ & \\
\hline Less religious group & $718(17.1 \%)$ & $171(23.8 \%)$ & $547(76.2 \%)$ & \\
\hline High delirium & $718(100 \%)$ & $171(23.8 \%)$ & $547(76.2 \%)$ & $1.000^{\mathrm{a}}$ \\
\hline
\end{tabular}

${ }^{\text {a }}$ Chi square $\left(\chi^{2}\right)$ test

\section{Discussion}

\section{Delirium}

The incidence and prevalence of delirium are high in ICU patients, with higher rates among mechanically ventilated patients (Bashar et al. 2018). The incidence and prevalence among ICU patients have been reported at $45-87 \%$ and $32 \%$, respectively (Ely et al. 2001a, b; Roberts et al. 2005; Salluh et al. 2010; Thomason et al. 2005), rates considerably higher than those reported for general medical 
Table 10 Religious status as a mortality predictor, with delirium (binary) as fixed variable

\begin{tabular}{|c|c|c|c|c|}
\hline \multirow[t]{3}{*}{ Delirium (binary)/religious status } & \multirow{3}{*}{$\begin{array}{l}\text { All stud- } \\
\text { ied patients } \\
(N=4200) \\
\text { No. }(\%)\end{array}$} & \multicolumn{2}{|l|}{ Outcome } & \multirow[t]{3}{*}{$p$ Value } \\
\hline & & Death $(N=1169)$ & Alive $(N=3031)$ & \\
\hline & & No. $(\%)$ & No. $(\%)$ & \\
\hline Less delirium group & $2030(48.3 \%)$ & $568(28 \%)$ & $1462(72 \%)$ & \\
\hline More religious & $1512(74.5 \%)$ & $432(28.6 \%)$ & $1080(71.4 \%)$ & $0.311^{\mathrm{a}}$ \\
\hline Moderate religious & $518(25.5 \%)$ & $136(26.3 \%)$ & $382(73.7 \%)$ & \\
\hline High delirium group & $2170(51.7 \%)$ & $601(27.7 \%)$ & $1569(72.3 \%)$ & \\
\hline More religious & $192(8.8 \%)$ & $63(32.8 \%)$ & $129(67.2 \%)$ & $0.003^{\mathrm{b}}$ \\
\hline Moderate religious & $1260(58.1 \%)$ & $367(29.1 \%)$ & $893(70.9 \%)$ & \\
\hline Less religious & $718(33.1 \%)$ & $171(23.8 \%)$ & $547(76.2 \%)$ & \\
\hline
\end{tabular}

$p<0.05$ is significant

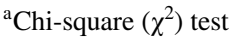

${ }^{\mathrm{b}} \chi^{2}$ test for trend

patients (incidence 29-31\%; prevalence 11-25\%) (Francis et al. 1990; Levkoff et al. 1991, 1992; O’Keeffe and Lavan 1997).

Delirium significantly impacts the morbidity and mortality of patients. Shortterm implications include prolonged ICU and hospital LOS, and increased likelihood of functional decline, hospital-acquired complications, and admission to longterm care (O'Keeffe and Lavan 1997). ICU delirium has been linked to increased MV duration, higher rates of self-extubation, and increased mortality (Ely et al. 2004). Longer-term complications include chronic cognitive impairment and functional disability. Moreover, delirium exacts a high financial cost. It is estimated that delirium is responsible for up to $\$ 64,000$ of additional healthcare costs per patient with delirium per year; thus, total direct 1-year healthcare costs attributable to delirium might range from $\$ 38$ billion to up to $\$ 152$ billion nationally (Leslie et al. 2008). The cost associated with delirium in mechanically ventilated patients in the US is around 4-16 billion dollars per year (Milbrandt et al. 2004).

A systematic review of six observational studies evaluated risk factors for ICU delirium and identified twenty-five risk factors, four of which were recognized as predisposing, whereas twenty-one were considered precipitating. The predisposing risk factors included respiratory disease, older age, alcohol abuse, and dementia; the precipitating factors included electrolyte abnormalities, fever, vasopressor requirement, increasing opiate dose, and metabolic acidosis (Van Rompaey et al. 2008). Besides opiates, the other classes of medications commonly associated with delirium include anti-cholinergic agents and benzodiazepines (Alagiakrishnan and Wiens 2004).

\section{Religiosity and Spirituality}

R/S are broadly defined as feelings, thoughts, experiences, and behaviors that arise from searching for the "sacred," with the former implying group or social practices 
and doctrines, and the latter referring to personal experiences and beliefs (Chida et al. 2009). It has been reported that approximately $90 \%$ of Iranians (USA 84\%) report a religious affiliation, and $96 \%$ of Iranians (USA 82\%) report religion as at least somewhat or very important in their lives (Hajiesmaeili et al. 2016; The Pew Research Center 2008). Several systematic reviews of the literature support a relationship between religiosity promoting improved health behaviors (Oji et al. 2017; Saad and Medeiros 2017) and lower all-cause mortality (Hatah et al. 2015; McCullough et al. 2000; Powell et al. 2003; Saad and Medeiros 2017). Emerging evidence suggests that R/S are correlated with improved mental and physical health outcomes, including decreased rates of depression (Bonelli et al. 2012; El-Hady and Kandeel 2017; Frih et al. 2017; Kazemi and Baharami 2014; Saisunantararom et al. 2015), anxiety, post-traumatic stress disorder, suicide, and coronary heart disease (Bashar et al. 2018).

Additionally, research in Muslim populations suggests that religious practice may generate physiologic changes that are clinically evident. Recitations of Qur'ān verses and the 99 names of Allah (God) to ill patients, for example, are practiced by many Muslims as a form of healing and worship (Ariff et al. 2013; Yadak et al. 2019). This practice has been reported to decrease perioperative pain (Avazeh et al. 2011; Mirzaeian et al. 2017) and anxiety (Atari et al. 2000; Avazeh et al. 2011; Hassan and Othman 2013; Hosseini et al. 2013; Majidi 2004; Tajvidi et al. 2001). The mechanism may in part be due to alpha wave generation as demonstrated on electroencephalogram (Hassan and Othman 2013; Abdullah and Omar 2011). The effects of Qur'ānic recitation or Zikr meditation on heart rate, blood pressure, mean arterial pressure, respiratory rate, and peripheral capillary oxygen saturation have been mixed (Abu Bakr 2014; Ajorpaz and Aghajani 2011; El-Hady and Kandeel 2017; Mansouri et al. 2017; Mirzaeian et al. 2017; Ariff et al. 2013; Sitepu 2009), although it has been suggested that repeated exposure may result in changes that are not evident the first time (Ildar et al. 2003; Mansouri et al. 2017).

\section{Morbidity and Mortality}

In this study, we found that the less religious group (self- or family reported) had more delirious shifts, higher delirium scores, longer MV duration, longer ICU and hospital LOS, and lower mortality. These findings warrant further discussion considering the literature, especially as it pertains to mortality.

Like prior reports, we found that greater delirium severity was associated with longer ICU and hospital LOS (Ely et al. 2004; Ouimet et al. 2007). However, ICU LOS has not been shown to be an independent risk factor for in-hospital mortality (Williams et al. 2010). Reports on the impact of delirium on mortality have been mixed, suggesting other confounding factors may be at play as well (Ely et al. 2004; Ouimet et al. 2007). As delirium-associated mortality has not previously been described in Iranian cohorts, the current study is the first to provide insight into this understudied aspect of delirium in Iranian ICUs.

Based on the literature, potential confounding factors that may be associated with delirium severity and/or mortality include: sex, age, smoking status, comorbidities, 
illness severity, sedation, restraints, duration of MV, ICU LOS, hospital LOS, nurseto-patient ratio, and physician-to-patient ratio.

In this cohort, the percentage of female patients was higher in the less religious group. Whereas some have reported that male sex may contribute to higher ICU mortality (Reinikainen et al. 2005), others have reported that values converge beyond 50 years of age (Mahmood et al. 2012). As the mean age in each group far exceeded this, it remains unclear whether sex contributed to the observed mortality differences.

In the multivariate analysis, tobacco use was also associated with mortality. Numerous studies estimate the smoking prevalence in Iran to be 10.5-22.9\% (Ghouri et al. 2006; Meysamie et al. 2010; Moosazadeh et al. 2013; Moosazadeh 2013). Data regarding the accuracy of self versus proxy reporting of smoking in Iran are lacking. Moreover, whether smoking is viewed as prohibited (harām) or simply discouraged (makrüh) varies greatly by region and sect (Ghouri et al. 2006). Further discussion of origins and types of Islamic moral law ( $\left.\operatorname{sharì}^{\prime} a h\right)$ that allow for these divergent interpretations is outside the scope of this manuscript; however, we have previously outlined the basics of Islamic jurisprudence elsewhere (Miller et al. 2014; Miller 2016). As the numbers observed in this cohort were higher than prior reports of regional and national prevalence, coupled with the fact that the data were gathered in a de-identified fashion, we believe the tobacco use measurements in this cohort to be accurate. In one US report, the discrepancy between proxy report and self-report has been reported to be $4.3 \%$, with the greatest discrepancy when the self-respondent reported non-daily smoking or recent quitting (Gilpin et al. 1994).

Similarly, advanced age has been correlated with delirium incidence and patient mortality. In a multivariate analysis, we similarly found increasing age to correlate significantly with greater delirium severity, greater sedation doses, and greater inhospital mortality. However, some have suggested that the nature of the admission and severity of illness, but not age, are determinants of ICU survival (Ryan et al. 2008). Illness severity can be recorded in many ways; one commonly used and validated means is by reporting the APACHE II score. An increase in APACHE II score is associated with increased mortality (Barie et al. 1995; Capuzzo et al. 2000; Del Bufalo et al. 1995; Ho et al. 2006; Katsaragakis et al. 2000; Khwannimit and Geater 2007; Naved et al. 2011; Ratanarat et al. 2005). Moreover, the APACHE II score has been reported to outperform both the Sequential Organ Failure Assessment (SOFA) score and Charlson Comorbidity Index (CCI) in predicting in-hospital mortality in ICU patients (Ho et al. 2007; Quach et al. 2009). In a multivariate analysis, we similarly found APACHE II score to correlate with patient mortality; however, as scores were similar across groups, this variable is unlikely to account for the mortality difference. Although we did not calculate the CCI, a listing of the most frequent comorbidities is provided (Table 6). It is known that with each chronic comorbidity, mortality increases (de Groot et al. 2003; Librero et al. 1999), and in a multivariate analysis, we similarly found that the number of comorbidities correlated with mortality.

The role that sedatives and physical restraints play in both precipitating and treating delirium while maintaining patient safety represents a confluence of intersecting and often opposing forces. The higher sedation doses in the less religiosity group 
are likely in response to the greater severity of delirium observed in this group. In a within-group analysis of delirium (binary categorization), it was observed that patients that died had less delirium and required less sedation. We hypothesize that this may in part be due to a decline in neurologic status necessitating lower sedation requirements prior to death.

Like the use of sedation, the use of physical restraints also corresponded to delirium severity, and thus, rates were higher in the less religiosity group. It is unclear whether other factors may have contributed to the discrepancy in physical restraint use, as the psychological effects of physical restraints may include anxiety, panic, increased agitation, fear, anger, depression, lethargy, and withdrawal (Kapp 1996; Martin 2002; Reigle 1996). The use of physical restraints for delirium is not a heavily researched topic in Iran. In two reports by the same group, Moradimajd et al. reported that adherence to routine restraint standards and guidelines ranged from 47.6 to $56.7 \%$ but rose to $73.3 \%$ following an educational intervention (Moradimajd et al. 2015, 2016). Although suboptimal, this is less an Iranian issue and more a reflection of the dismal state of education and documentation regarding physical restraints that has similarly been reported in other regions including Asia, Oceana, and the USA, where one study showed that nurses were lacking in their knowledge of restraints and that education changed their perception, leading to a $60 \%$ reduction in their use (Choi and Song 2003; Swauger and Tomlin 2000; Whitehead et al. 1997).

ICU staffing has also been shown to impact patient mortality. It has been reported that a high nurse-to-patient ratio (e.g., greater than 1:1.5) is independently associated with a lower risk of in-hospital death (Cho et al. 2008; Sakr et al. 2015). For instance, every additional patient per nurse may increase the odds of patient mortality by $9 \%$ (Cho et al. 2008). In the current study sites, the nurse-to-patient ratio was 1:2. Although this was equal between groups and would not have affected inter-group comparisons, it could have increased overall mortality within the study. Moreover, physician staffing may be a significant factor contributing to patient mortality. A meta-analysis found that high-intensity staffing (mandatory intensivist consultation or closed ICU) was associated with lower ICU mortality in 14 of 15 studies (93\%) and lower hospital mortality in 16 of 17 studies (94\%) (Pronovost et al. 2002). High-intensity staffing also reduced ICU and hospital LOS (Pronovost et al. 2002). This is not the case in the current study due to healthcare system and logistical impediments. Although a high-intensity staffing model was used at the study sites, the outpatient and subacute rehabilitation industries are less developed than in many Western nations. Therefore, much of what might be outpatient rehab in Western nations is shifted to the inpatient setting in Iran, thereby prolonging the overall hospital LOS.

Next, the role of family members in the care of critically ill patients with delirium in Iran warrants examination. Family members in Iran have been described as an enthusiastic unpaid volunteer labor force that works to improve the quality of care for their family members (Vahedian-Azimi et al. 2015). Patients receive significant unskilled and non-professional nursing care from their family members (Khosravan et al. 2014). Moreover, most nurses and families believe that family participation is both voluntary and compulsory (Khosravan et al. 2014). There is an emphasis on 
communication between staff and family members allowing staff to better understand the patient's habits and mannerisms so as to speed up patient-related affairs and enable better management of the patient's condition (Khosravan et al. 2014; Vahedian-Azimi et al. 2015). There is no evidence that the patient's level of religiosity impacts the level of family participation, and thus, any impact on delirium severity would have been equal across each tertile of religiosity.

It remains unclear whether and to what degree patient/family religiosity influenced their choice to pursue given treatment paths (e.g., life sustaining therapies). What constitutes a "good death" differs greatly between regions, cultures, religions, and personal beliefs (Tayeb et al. 2010). Not surprisingly, aspects of a good death may differ significantly between Muslim majority regions and the West (Tayeb et al. 2010). Data from Iran are not available, but in a study of patients in Saudi Arabia, one aspect of a good death was "to be able to leave when it is time to go, and not to have life prolonged pointlessly" (Tayeb et al. 2010). The potential interaction of faith and end-of-life treatment choices in Iran warrants further investigation.

Lastly, one's ability to cope with stress may be an important factor when assessing delirium. Unfortunately, the ability to cope with stress was not one of the defined study endpoints. Resiliency is a complex psychometric construct describing a person's ability to positively adapt to a stressful or traumatic situation and is composed of traits including optimism, cognitive flexibility, and adaptive coping mechanisms. Established survey instruments such as the COPE, Brief COPE, and the Utrechtse Coping List (UCL) are lengthy, designed for the general population, and have not been validated in the critically ill. The validated, short, critical care focused survey instrument developed by Boezeman and colleagues entitled the Sickness Insight in Coping Questionnaire (SICQ) was published after this study was conducted (Boezeman et al. 2016). This tool will be considered for future studies.

\section{Conclusion}

Patients with high religiosity had fewer delirious shifts, lower delirium scores, shorter duration of mechanical ventilation, shorter hospital and ICU length of stays, but higher mortality when compared to patients with less religiosity. In multivariate analysis factors associated with increased mortality included male sex, age, smoking status, comorbidities, illness severity, sedation, restraints, duration of MV, ICU LOS, hospital LOS, nurse-to-patient ratio, and physician-to-patient ratio. The lower mortality in the less religiosity group may be related in part to a greater proportion of female patients, but it remains unclear whether and to what extent greater religiosity impacted decisions by patients and families to initiate or continue life prolonging treatments rather than accepting a more natural death.

Acknowledgements None.

\section{Compliance with Ethical Standards}

Conflict of interest The authors declare that they have no conflicts of interest. 


\section{References}

Abdullah, A. A., \& Omar, Z. (2011). The effect of temporal EEG signals while listening to Quran recitation. International Journal on Advanced Science, Engineering and Information Technology, 1(4), 372. https://doi.org/10.18517/ijaseit.1.4.77.

Ajorpaz, N. M., \& Aghajani, M. (2011). The effects of music and holy quran on patients' anxiety and vital signs before abdominal surgery. Evidence Based Care, 1(1), 63-76. https://doi. org/10.22038/EBCJ.2011.3765.

Alagiakrishnan, K., \& Wiens, C. A. (2004). An approach to drug induced delirium in the elderly. Postgraduate Medicine Journal, 80(945), 388-393. https://doi.org/10.1136/pgmj.2003.017236.

Al-Qadheeb, N. S., Skrobik, Y., Schumaker, G., Pacheco, M. N., Roberts, R. J., Ruthazer, R. R., et al. (2016). Preventing ICU subsyndromal delirium conversion to delirium with low-dose IV haloperidol: A double-blind, placebo-controlled pilot study. Critical Care Medicine, 44(3), 583-591. https://doi.org/10.1097/CCM.0000000000001411.

Alves, R. R., Alves, H. N., Barboza, R. R., \& Souto, W. M. (2010). The influence of religiosity on health. Ciência \& Saúde Coletiva, 15(4), 2105-2111. https://doi.org/10.1590/S1413-81232 010000400024.

American Psychiatry Association. (2013). Diagnostic and statistical manual (5th ed.). Washington, DC: APA Press.

Ariff, M. S., Mai Ashikin, N. T., Maryamjameelah, R., Bushra, J., \& Wan Azman, W. A. (2013). Pilot study on the effect of Yasiin recitation on the haemodynamics of ventilated patients. International Medical Journal Malaysia, 12(2), 45-49.

Atari, M. A., Sajedi, P., \& Heydari, S. M. (2000). Evaluation of Koran voices effect on anxiety and vital signs of patients in preinduction stage. Teb Va Tazkieh, 37, 91-94.

Atef-Vahid, M., Nasr-Esfahani, M., Esfeedvajani, M. S., Naji-Isfahani, H., Shojaei, M. R., Masoumeh, Y. M., et al. (2011). Quality of life, religious attitude and cancer coping in a sample of Iranian patients with cancer. Journal of Research in Medical Sciences, 16(7), 928-937.

Avazeh, A., Ghorbani, F., Vahedian-Azimi, A., Siahkali, S. R., Khodadadi, M. T., \& Mahdizadeh, S. (2011). Evaluation of the effect of reciting the word "Allah" on the pain and anxiety of dressing change in burn patients. Quran and Medicine, 1(2), 36-39. https://doi.org/10.5812/quranmed.4973.

Azimi-Nezhad, M., Ghayour-Mobarhan, M., Parizadeh, M. R., Safarian, M., Esmaeili, H., Parizadeh, S. M., et al. (2008). Prevalence of type 2 diabetes mellitus in Iran and its relationship with gender, urbanisation, education, marital status and occupation. Singapore Medical Journal, 49(7), $571-576$.

Bagiella, E., Hong, V., \& Sloan, R. P. (2005). Religious attendance as a predictor of survival in the EPESE cohorts. International Journal of Epidemiology, 34(2), 443-451. https://doi.org/10.1093/ ije/dyh396.

Bakr, S. A. B. A. (2014). Effects of holy quran listening on physiological stress response among muslim patients in intensive care unit. In Conference on management and muamalah (CoMM 2014). Kolej Universiti Islam Antarabangsa Selangor, Selangor, Malaysia.

Balboni, T. A., Balboni, M., Enzinger, A. C., Gallivan, K., Paulk, M. E., Wright, A., et al. (2013). Provision of spiritual support to patients with advanced cancer by religious communities and associations with medical care at the end of life. JAMA Internal Medicine, 173(12), 1109-1117. https:// doi.org/10.1001/jamainternmed.2013.903.

Barie, P. S., Hydo, L. J., \& Fischer, E. (1995). Comparison of APACHE II and III scoring systems for mortality prediction in critical surgical illness. Archives of Surgery, 130(1), 77-82. https://doi. org/10.1001/archsurg.1995.01430010079016.

Bashar, F. R., Vahedian-Azimi, A., Salesi, M., Hajiesmaeili, M., Shojaei, S., Farzanegan, B., et al. (2018). Spiritual health and outcomes in Muslim ICU patients: A nationwide cross-sectional study. Journal of Religion and Health, 57(6), 2241-2257. https://doi.org/10.1007/s10943-017-0543-5.

Boezeman, E. J., Hofhuis, J. G., Hovingh, A., Cox, C. E., de Vries, R. E., \& Spronk, P. E. (2016). Measuring adaptive coping of hospitalized patients with a severe medical condition: The sickness insight in coping questionnaire. Critical Care Medicine, 44(9), e818-e826. https://doi.org/10.1097/ CCM.0000000000001743.

Bonelli, R., Dew, R. E., Koenig, H. G., Rosmarin, D. H., \& Vasegh, S. (2012). Religious and spiritual factors in depression: Review and integration of the research. Depression Research and Treatment, 2012, 962860. https://doi.org/10.1155/2012/962860. 
Bulow, H., Sprung, C. L., Baras, M., Carmel, S., Svantesson, M., Benbenishty, J., et al. (2012). Are religion and religiosity important to end-of-life decisions and patient autonomy in the ICU? The Ethicatt study. Intensive Care Medicine, 38(7), 1126-1133. https://doi.org/10.1007/s0013 4-012-2554-8.

Callender, T., Woodward, M., Roth, G., Farzadfar, F., Lemarie, J. C., Gicquel, S., et al. (2014). Heart failure care in low-and middle-income countries: A systematic review and meta-analysis. PLoS Medicine, 11(8), e1001699. https://doi.org/10.1371/journal.pmed.1001699.

Capuzzo, M., Valpondi, V., Sgarbi, A., Bortolazzi, S., Pavoni, V., Gilli, G., et al. (2000). Validation of severity scoring systems SAPS II and APACHE II in a single-center population. Intensive Care Medicine, 26(12), 1779-1785. https://doi.org/10.1007/s001340000715.

Chida, Y., Steptoe, A., \& Powell, L. H. (2009). Religiosity/spirituality and mortality. A systematic quantitative review. Psychotherapy and Psychosomatics, 78(2), 81-90. https://doi.org/10.1159/00019 0791.

Cho, S., Hwang, J. H., \& Kim, J. (2008). Nurse staffing and patient mortality in intensive care units. Nursing Research, 57(5), 322-330. https://doi.org/10.1097/01.NNR.0000313498.17777.71.

Choi, E., \& Song, M. (2003). Physical restraint use in a Korean ICU. Journal of Clinical Nursing, 12(5), 651-659. https://doi.org/10.1046/j.1365-2702.2003.00789.x.

Darviri, C., Artemiadis, A., Tigani, X., Darvyri, P., \& Gnardellis, C. (2016). Religiosity as a predictor of mortality: A retrospective cohort study in 1519 rural citizens in Greece. Psychology and Health, 31(9), 1080-1090. https://doi.org/10.1080/08870446.2016.1178744.

de Groot, V., Beckerman, H., Lankhorst, G. J., \& Bouter, L. M. (2003). How to measure comorbidity: A critical review of available methods. Journal of Clinical Epidemiology, 56(3), 221-229. https://doi. org/10.1016/S0895-4356(02)00585-1.

Del Bufalo, C., Morelli, A., Bassein, L., Fasano, L., Quarta, C. C., Pacilli, A. M., et al. (1995). Severity scores in respiratory intensive care: APACHE II predicted mortality better than SAPS II. Respiratory Care, 40(10), 1042-1047.

Devlin, J. W., Al-Qadhee, N. S., \& Skrobik, Y. (2012). Pharmacologic prevention and treatment of delirium in critically ill and non-critically ill hospitalised patients: A review of data from prospective, randomised studies. Best Practice and Research Clinical Anaesthesiology, 26(3), 289-309. https:// doi.org/10.1016/j.bpa.2012.07.005.

El-Hady, M. M., \& Kandeel, N. A. (2017). The effect of listening to Qur'an on physiological responses of mechanically ventilated Muslim patients. IOSR Journal of Nursing and Health Science, 6(5), 79-87. https://doi.org/10.9790/1959-0605097987.

Ellison, C. G., \& Levin, J. S. (1998). The religion-health connection: Evidence, theory, and future directions. Health Education and Behavior, 25(6), 700-720. https://doi.org/10.1177/109019819802500 603.

Ely, E. W., Margolin, R., Francis, J., May, L., Truman, B., Dittus, R., et al. (2001a). Evaluation of delirium in critically ill patients: Validation of the confusion assessment method for the intensive care unit (CAM-ICU). Critical Care Medicine, 29(7), 1370-1379. https://doi.org/10.1097/00003246200107000-00012.

Ely, E. W., Shintani, A., Truman, B., Speroff, T., Gordon, S. M., Harrell, F. E., et al. (2004). Delirium as a predictor of mortality in mechanically ventilated patients in the intensive care unit. JAMA, 291(14), 1753-1762. https://doi.org/10.1001/jama.291.14.1753.

Ely, E. W., Siegel, M., \& Inouye, S. (2001b). Delirium in the intensive care unit: An under-recognized syndrome of organ dysfunction. Seminars in Respiratory and Critical Care Medicine, 22(2), 115126. https://doi.org/10.1055/s-2001-13826.

Faul, F., Erdfelder, E., Buchner, A., \& Lang, A. (2009). Statistical power analyses using GPower 3.1: Tests for correlation and regression analyses. Behavior Research Methods, 41(4), 1149-1160. https ://doi.org/10.3758/brm.41.4.1149.

Forghanizadeh, J., Abhari, R., Shakibi, M. R., Samadi, F., Oiroozian, M., \& Tavakoli, S. (1995). Prevalence of rheumatic diseases in Fasham. Razi Journal of Medical Sciences, 2(1), 182-191.

Francis, J., Martin, D., \& Kapoor, W. N. (1990). A prospective study of delirium in hospitalized elderly. JAMA, 263(8), 1097-1101. https://doi.org/10.1001/jama.1990.03440080075027.

Frih, B., Mkacher, W., Bouzguenda, A., Jaafar, H., Alkandari, S. A., Salah, Z. B., et al. (2017). Effects of listening to holy Qur'an recitation and physical training on dialysis efficacy, functional capacity, and psychosocial outcomes in elderly patients undergoing haemodialysis. Libyan Journal of Medicine, 12(1), 1372032. https://doi.org/10.1080/19932820.2017.1372032. 
Ganji, A., Malekzadeh, F., Safavi, M., Moghaddam, S. N., Nouraie, M., Merat, S., et al. (2009). Digestive and liver disease statistics in Iran. Middle East Journal of Digestive Diseases, 1(2), 56-62. https:// doi.org/10.15171/middle\%20east\%20j\%20di.v1i2.427.

Ghouri, N., Atcha, M., \& Sheikh, A. (2006). Influence of Islam on smoking among Muslims. BMJ, 332(7536), 291-294. https://doi.org/10.1136/bmj.332.7536.291.

Gilpin, E. A., Pierce, J. P., Cavin, S. W., Berry, C. C., Evans, N. J., Johnson, M., et al. (1994). Estimates of population smoking prevalence: Self-vs proxy reports of smoking status. American Journal of Public Health, 84(10), 1576-1579. https://doi.org/10.2105/AJPH.84.10.1576.

Gleason, L. J., Schmitt, E. M., Kosar, C. M., Tabloski, P., Saczynski, J. S., Robinson, T., et al. (2015). Effect of delirium and other major complications on outcomes after elective surgery in older adults. JAMA Surgery, 150(12), 1134-1140. https://doi.org/10.1001/jamasurg.2015.2606.

Hajiesmaeili, M. R., Abbasi, M., Safaiepour, L., Fani, M., Abdoljabari, M., Hosseini, S. M., et al. (2016). Spiritual health concept in Iranian society: Evolutionary concept analysis and narrative review. Medical Ethics Journal, 10(35), 77-115. https://doi.org/10.21859/mej-103577.

Hassan, A. O., \& Othman, S. A. (2013). Effects of Quran listening and music on electroencephalogram brain waves. Egypt Journal of Experimental Biology, 9(1), 119-121.

Hatah, E., Lim, K. P., Ali, A. M., Mohamed Shah, N., \& Islahudin, F. (2015). The influence of cultural and religious orientations on social support and its potential impact on medication adherence. Patient Preference and Adherence, 9, 589-596. https://doi.org/10.2147/PPA.S79477.

Ho, K. M., Dobb, G. J., Knuiman, M., Finn, J., Lee, K. Y., \& Webb, S. A. R. (2006). A comparison of admission and worst 24-hour acute physiology and chronic health evaluation II scores in predicting hospital mortality: A retrospective cohort study. Critical Care, 10(1), R4. https://doi.org/10.1186/ cc3913.

Ho, K. M., Lee, K. Y., Williams, T., Finn, J., Knuiman, M., \& Webb, S. A. R. (2007). Comparison of acute physiology and chronic health evaluation (APACHE) II score with organ failure scores to predict hospital mortality. Anaesthesia, 62(5), 466-473. https://doi.org/10.1111/j.1365-2044.2007.04999 .x.

Hosseini, M., Salehi, A., Fallahi Khoshknab, M., Rokofian, A., \& Davidson, P. M. (2013). The effect of a preoperative spiritual/religious intervention on anxiety in Shia Muslim patients undergoing coronary artery bypass graft surgery. Journal of Holistic Nursing, 31(3), 164-172. https://doi. org/10.1177/0898010113488242.

Ildar, A. E., Saleh, M. A. R., \& Mazloom, S. R. (2003). The effect of Holy Quran recitation on the patient's vital signs before open heart surgery. J Sabzevar Univ Med Sci, 10(1/27), 52-58.

Ironson, G., Kremer, H., \& Lucette, A. (2016). Relationship between spiritual coping and survival in patients with HIV. Journal of General Internal Medicine, 31(9), 1068-1076. https://doi. org/10.1007/s11606-016-3668-4.

Jazayeri, S. B., Rahimi-Movaghar, V., Shokraneh, F., Saadat, S., \& Ramezani, R. (2013). Epidemiology of primary CNS tumors in Iran: A systematic review. Asian Pacific Journal of Cancer Prevention, 14(6), 3979-3985. https://doi.org/10.7314/APJCP.2013.14.6.3979.

Kalabalik, J., Brunetti, L., \& El-Srougy, R. (2014). Intensive care unit delirium. Journal of Pharmacy Practice, 27(2), 195-207. https://doi.org/10.1177/0897190013513804.

Kapp, M. B. (1996). Physical restraint use in critical care: Legal issues. AACN Advanced Critical Care, 7(4), 579-584. https://doi.org/10.1097/00044067-199611000-00013.

Katsaragakis, S., Papadimitropoulos, K., Antonakis, P., Strergiopoulos, S., Konstadoulakis, M., \& Androulakis, G. (2000). Comparison of acute physiology and chronic health evaluation II (APACHE II) and simplified acute physiology score II (SAPS II) scoring systems in a single greek intensive care unit. Critical Care Medicine, 28(2), 426-432. https://doi.org/10.1097/00003246200002000-00023.

Kazemi, M., \& Baharami, B. (2014). The role of spiritual belief and Islamic practice in improvement of mental health and prevention of mental disorders. Journal of Zanjan University of Medical Sciences and Health Services, 22(90), 62-74.

Khosravan, S., Mazlom, B., Abdollahzade, N., Jamil, Z., \& Mansoorian, M. R. (2014). Family participation in the nursing care of the hospitalized patients. Iranian Red Crescent Medical Journal, 16(1), e12686. https://doi.org/10.5812/ircmj.12868.

Khwannimit, B., \& Geater, A. (2007). A comparison of APACHE II and SAPS II scoring systems in predicting hospital mortality in thai adult intensive care units. Journal of the Medical Association of Thailand, 90(4), 643-652. 
Leslie, D. L., Marcantonio, E. R., Zhang, Y., Leo-Summers, L., \& Inouye, S. K. (2008). One-year health care costs associated with delirium in the elderly population. Archives of Internal Medicine, 168(1), 27-32. https://doi.org/10.1001/archinternmed.2007.4.

Levkoff, S., Cleary, P., Liptzin, B., \& Evans, D. A. (1991). Epidemiology of delirium: An overview of research issues and findings. International Psychogeriatrics, 3(2), 149-167. https://doi. org/10.1017/S1041610291000625.

Levkoff, S. E., Evans, D. A., Liptzin, B., Cleary, P. D., Lipsitz, L. A., Wetle, T. T., et al. (1992). Delirium: The occurrence and persistence of symptoms among elderly hospitalized patients. Archives of Internal Medicine, 152(2), 334-340. https://doi.org/10.1001/archinte.1992.00400140082019.

Librero, J., Peiró, S., \& Ordiñana, R. (1999). Chronic comorbidity and outcomes of hospital care: Length of stay, mortality, and readmission at 30 and 365 days. Journal of Clinical Epidemiology, 52(3), 171-179. https://doi.org/10.1016/S0895-4356(98)00160-7.

Mahmood, K., Eldeirawi, K., \& Wahidi, M. M. (2012). Association of gender with outcomes in critically ill patients. Critical Care, 16(3), R92. https://doi.org/10.1186/cc11355.

Majidi, S. A. (2004). Recitation effect of Holy Quran on anxiety of patients before undergoing coronary artery angiography. Journal of Guilan University of Medical Sciences, 13(49), 61-67.

Mansouri, A., Vahed, A. S., Sabouri, A. R., Lakzaei, H., \& Arbabisarjou, A. (2017). Investigating aid effect of Holy Quran sound on blood pressure, pulse, respiration and $\mathrm{O} 2$ sat in ICU patients. International Journal of Scientific Study, 5(7), 218-222. https://doi.org/10.17354/ijssnov/2017/29.

Marcantonio, E. R., Kiely, D. K., Simon, S. E., John Orav, E., Jones, R. N., Murphy, K. M., et al. (2005). Outcomes of older people admitted to postacute facilities with delirium. Journal of the American Geriatrics Society, 53(6), 963-969. https://doi.org/10.1111/j.1532-5415.2005.53305.x.

Mardiyono, M., Songwathana, P., \& Petpichetchian, W. (2011). Spirituality intervention and outcomes: Corner stone of holistic nursing practice. Nurse Media Journal of Nursing, 1(1), 117-127. https:// doi.org/10.14710/nmjn.v1i1.751.

Martin, B. (2002). Restraint use in acute and critical care settings: Changing practice. AACN Advanced Critical Care, 13(2), 294-306. https://doi.org/10.1097/00044067-200205000-00013.

McCullough, M. E., Hoyt, W. T., Larson, D. B., Koenig, H. G., \& Thoresen, C. (2000). Religious involvement and mortality: A meta-analytic review. Health Psychology, 19(3), 211-222. https://doi. org/10.1037//0278-6133.19.3.211.

Mehta, S., Cook, D., Devlin, J., Skrobik, Y., Meade, M., Fergusson, D., et al. (2015). Prevalence, risk factors, and outcomes of delirium in mechanically ventilated adults. Critical Care Medicine, 43(3), 557-566. https://doi.org/10.1097/CCM.0000000000000727.

Meysamie, A., Ghaletaki, R., Haghazali, M., Asgari, F., Rashidi, A., Khalilzadeh, O., et al. (2010). Pattern of tobacco use among the iranian adult population: Results of the national survey of risk factors of non-communicable diseases (SuRFNCD-2007). Tobacco Control, 19(2), 125-128. https:// doi.org/10.1136/tc.2009.030759.

Milbrandt, E., Deppen, S., Harrison, P., Shintani, A., Speroff, T., Stiles, R., et al. (2004). Costs associated with delirium in mechanically ventilated patients. Critical Care Medicine, 32(4), 955-962. https:// doi.org/10.1097/01.CCM.0000119429.16055.92.

Miller, A. C. (2016). Opinions on the legitimacy of brain death among Sunni and Shi' a scholars. Journal of Religion and Health, 55(2), 394-402. https://doi.org/10.1007/s10943-015-0157-8.

Miller, R. D, Eriksson, L., Fleisher, L., Weiner-Kronish, J., Cohen, N., \& Young, W. (2015). Miller's Anesthesia (8th edn.). Philadelphia: Elsevier Churchill Livingston.

Miller, A. C., Ziad-Miller, A., \& Elamin, E. M. (2014). Brain death and Islam: The interface of religion, culture, history, law, and modern medicine. Chest, 146(4), 1092-1101. https://doi.org/10.1378/ chest.14-0130.

Mirzaeian, R., Shirvani, M., Slidosti, M., \& Babaei-Heydarabadi, A. (2017). The effect of Holy Quran recitation sound on vital signs and arterial oxygen pressure of unconscious patients in the ICU. Indo American Journal of Pharmaceutical Sciences, 4(5), 1254-1259.

Moosazadeh, M. (2013). Meta-analysis of prevalence of smoking in 15-64-year-old population of west of Iran. International Journal of Preventive Medicine, 4(10), 1108-1114.

Moosazadeh, M., Ziaaddini, H., Mirzazadeh, A., Ashrafi-Asgarabad, A., \& Haghdoost, A. A. (2013). Meta-analysis of smoking prevalence in Iran. Addiction and Health, 5(3-4), 140-153.

Moradimajd, P., Asadi Noghabi, A., Zolfaghari, M., \& Mehran, A. (2015). Physical restraint use in intensive care units. Iranian Journal of Critical Care Nursing, 8(3), 173-178.

Moradimajd, P., Asadi Noughabi, A. A., Zolfaghari, M., \& Meran, A. (2016). Effectiveness of multifactorial intervention on observance of physical restraint standards of the patients hospitalized 
in intensive care units. Journal of Critical Care Nursing, 9(2), e6359. https://doi.org/10.17795/ ccn-6359.

Nagaraj, S., Biswal, S., Boyle, E., Zhou, D., McClain, L., Bajwa, E., et al. (2017). Patient-specific classification of ICU sedation levels from heart rate variability. Critical Care Medicine, 45(7), e683e690. https://doi.org/10.1097/CCM.0000000000002364.

Nagaraj, S., McClain, L., Zhou, D., Biswal, S., Rosenthal, E., Purdon, P., et al. (2016). Automatic classification of sedation levels in ICU patients using heart rate variability. Critical Care Medicine, 44(9), e782-e789. https://doi.org/10.1097/CCM.0000000000001708.

Naved, S. A., Siddiqui, S., \& Khan, F. H. (2011). APACHE-II score correlation with mortality and length of stay in an intensive care unit. Journal of the College of Physicians and Surgeons Pakistan, 21(1), 4-8. https://doi.org/10.2011/JCPSP.0408.

Neto, A. S., Nassar, J., Cardoso, S. O., Manetta, J., Pereira, V., Espósito, D., et al. (2012). Delirium screening in critically ill patients: A systematic review and meta-analysis. Critical Care Medicine, 40(6), 1946-1951. https://doi.org/10.1097/CCM.0b013e31824e16c9.

Oji, V. U., Hung, L. C., Abbasgholizadeh, R., Terrell Hamilton, F., Essien, E. J., \& Nwulia, E. A. (2017). Spiritual care may impact mental health and medication adherence in HIV + populations. HIV AIDS, 9, 101-109. https://doi.org/10.2147/HIV.S126309.

O'Keeffe, S., \& Lavan, J. (1997). The prognostic significance of delirium in older hospital patients. Journal of the American Geriatrics Society, 45(2), 174-178. https://doi.org/10.1111/j.1532-5415.1997. tb04503.x.

Ouimet, S., Kavanagh, B., Gottfried, S., \& Skrobik, Y. (2007). Incidence, risk factors and consequences of ICU delirium. Intensive Care Medicine, 33(1), 66-73. https://doi.org/10.1007/s0013 4-006-0399-8.

Pandharipande, P. P., Girard, T. D., Jackson, J. C., Morandi, A., Thompson, J. L., Pun, B. T., et al. (2013). Long-term cognitive impairment after critical illness. New England Journal of Medicine, 369(14), 1306-1316. https://doi.org/10.1056/NEJMoa1301372.

Park, C. L., Aldwin, C. M., Choun, S., George, L., Suresh, D. P., \& Bliss, D. (2016). Spiritual peace predicts 5-year mortality in congestive heart failure patients. Health Psychology, 35(3), 203-210. https ://doi.org/10.1037/hea0000271.

Pereira, D. B., Christian, L. M., Patidar, S., Bishop, M. M., Dodd, S. M., Athanason, R., et al. (2010). Spiritual absence and 1-year mortality after hematopoietic stem cell transplant. Biology of Blood and Marrow Transplantation, 16(8), 1171-1179. https://doi.org/10.1016/j.bbmt.2010.03.003.

Pisani, M. A., Murphy, T. E., Araujo, K., \& Van Ness, P. H. (2010). Factors associated with persistent delirium after intensive care unit admission in an older medical patient population. Journal of Critical Care, 25(3), 540.e7. https://doi.org/10.1016/j.jcrc.2010.02.009.

Powell, L. H., Shahabi, L., \& Thoresen, C. E. (2003). Religion and spirituality linkages to physical health. American Psychologist, 58(1), 36-52. https://doi.org/10.1037/0003-066x.58.1.36.

Pronovost, P. J., Angus, D. C., Dorman, T., Robinson, K. A., Dremsizov, T. T., \& Young, T. L. (2002). Physician staffing patterns and clinical outcomes in critically ill patients: A systematic review. JAMA, 288(17), 2151-2162. https://doi.org/10.1001/jama.288.17.2151.

Quach, S., Hennessy, D. A., Faris, P., Fong, A., Quan, H., \& Doig, C. (2009). A comparison between the APACHE II and charlson index score for predicting hospital mortality in critically ill patients. BMC Health Services Research, 9(1), 129. https://doi.org/10.1186/1472-6963-9-129.

Ratanarat, R., Thanakittiwirun, M., Vilaichone, W., Thongyoo, S., \& Permpikul, C. (2005). Prediction of mortality by using the standard scoring systems in a medical intensive care unit in thailand. Journal of the Medical Association of Thailand, 88(7), 949-955.

Reigle, J. (1996). The ethics of physical restraints in critical care. AACN Advanced Critical Care, 7(4), 585-591. https://doi.org/10.1097/00044067-199611000-00014.

Reinikainen, M., Niskanen, M., Uusaro, A., \& Ruokonen, E. (2005). Impact of gender on treatment and outcome of ICU patients. Acta Anaesthesiologica Scandinavica, 49(7), 984-990. https://doi.org/10 .1111/j.1399-6576.2005.00759.x.

Roberts, B., Rickard, C. M., Rajbhandari, D., Turner, G., Clarke, J., Hill, D., et al. (2005). Multicentre study of delirium in ICU patients using a simple screening tool. Australian Critical Care, 18(1), 6-16. https://doi.org/10.1016/S1036-7314(05)80019-0.

Ryan, D., Conlon, N., Phelan, D., \& Marsh, B. (2008). The very elderly in intensive care: Admission characteristics and mortality. Critical Care and Resuscitation, 10(2), 106-110. 
Saad, M., \& Medeiros, R. (2017). Implications for public health of the religiosity-longevity relation. Revista Da Associacao Medica Brasileira, 63(10), 837-841. https://doi. org/10.1590/1806-9282.63.10.837.

Sadeghi, M., Roohafza, H., Shirani, S., Poormoghadas, M., Kelishadi, R., Baghaii, A., et al. (2007). Diabetes and associated cardiovascular risk factors in Iran: The Isfahan Healthy Heart Programme. Annals of the Academy of Medicine, Singapore, 36(3), 175-180.

Safarinejad, M. R. (2009). The epidemiology of adult chronic kidney disease in a population-based study in Iran: prevalence and associated risk factors. Journal of Nephrology, 22(1), 99-108.

Saisunantararom, W., Cheawchanwattana, A., Kanjanabuch, T., Buranapatana, M., \& Chanthapasa, K. (2015). Associations among spirituality, health-related quality of life, and depression in predialysis chronic kidney disease patients: An exploratory analysis in thai buddhist patients. Religions, 6(4), 1249-1262. https://doi.org/10.3390/rel6041249.

Sakr, Y., Moreira, C. L., Rhodes, A., Ferguson, N. D., Kleinpell, R., Pickkers, P., et al. (2015). The impact of hospital and ICU organizational factors on outcome in critically ill patients: Results from the extended prevalence of infection in intensive care study. Critical Care Medicine, 43(3), 519-526. https://doi.org/10.1097/CCM.0000000000000754.

Salluh, J. I., Soares, M., Teles, J. M., Ceraso, D., Raimondi, N., Nava, V. S., et al. (2010). Delirium epidemiology in critical care (DECCA): An international study. Critical Care, 14(6), R210. https://doi.org/10.1186/cc9333.

Schreiber, M., Colantuoni, E., Bienvenu, O., Neufeld, K., Chen, K., Shanholtz, C., et al. (2014). Corticosteroids and transition to delirium in patients with acute lung injury. Critical Care Medicine, 42(6), 1480-1486. https://doi.org/10.1097/CCM.0000000000000247.

Shehabi, Y., Riker, R. R., Bokesch, P. M., Wisemandle, W., Shintani, A., \& Ely, E. W. (2010). Delirium duration and mortality in lightly sedated, mechanically ventilated intensive care patients. Critical Care Medicine, 38(12), 2311-2318. https://doi.org/10.1097/CCM.0b013e3181f85759.

Shinall, J., Myrick, C., Ehrenfeld, J. M., \& Guillamondegui, O. D. (2014). Religiously affiliated intensive care unit patients receive more aggressive end-of-life care. Journal of Surgical Research, 190(2), 623-627. https://doi.org/10.1016/j.jss.2014.05.074.

Sitepu, N. F. (2009). Effect of Zikir meditation on postoperative pain among Muslim patients undergoing abdominal surgery (Masters Thesis). Prince of Songkla University. Medan, Indonesia. http://kb.psu.ac.th/psukb/bitstream/2010/5953/1/313829.pdf. Accessed 9 Jan 2019.

Sukantarat, K. T., Burgess, P. W., Williamson, R. C. N., \& Brett, S. J. (2005). Prolonged cognitive dysfunction in survivors of critical illness. Anaesthesia, 60(9), 847-853. https://doi.org/10.111 1/j.1365-2044.2005.04148.x.

Swauger, K., \& Tomlin, C. (2000). Moving toward restraint-free patient care. Journal of Nursing Administration, 30(6), 325-329. https://doi.org/10.1097/00005110-200006000-00011.

Tajvidi, M., Mohammadi, E., \& Memarian, R. (2001). The effect of Holy Quran's song on patient anxiety before the heart surgery. Daneshvar Medicine, 8(32), 55-60.

Talaei, M., Sarrafzadegan, N., Sadeghi, M., Oveisgharan, S., Marshall, T., Thomas, N., et al. (2013). Incidence of cardiovascular diseases in an Iranian population: The Isfahan cohort study. Archives of Iranian Medicine, 16(3), 138-144. https://doi.org/10.13163/AIM.004.

Tayeb, M. A., Al-Zamel, E., Fareed, M. M., \& Abouellail, H. A. (2010). A "good death": Perspectives of Muslim patients and health care providers. Annals of Saudi Medicine, 30(3), 215-221. https://doi. org/10.4103/0256-4947.62836.

The Pew Research Center. (2008). U.S. religious landscape survey: Religious affiliation. Washington D.C.: The Pew Research Center. https://www.pewforum.org/2008/02/01/u-s-religious-landscapesurvey-religious-affiliation/. Accessed 9 Jan 2019.

Thomason, J. W. W., Shintani, A., Peterson, J. F., Pun, B. T., Jackson, J. C., \& Ely, E. W. (2005). Intensive care unit delirium is an independent predictor of longer hospital stay: A prospective analysis of 261 non-ventilated patients. Critical Care, 9(4), R381. https://doi.org/10.1186/cc3729.

Trogrlic, Z., Jagt, M., Bakker, J., Balas, M. C., Ely, W. E., Voort, P., et al. (2015). A systematic review of implementation strategies for assessment, prevention, and management of ICU delirium and their effect on clinical outcomes. Critical Care, 19(1), 157. https://doi.org/10.1186/s13054-015-0886-9.

Trzepacz, P. T., Mittal, D., Torres, R., Kanary, K., Norton, J., \& Jimerson, N. (2001). Validation of the delirium rating scale-revised-98: Comparison with the delirium rating scale and the cognitive test for delirium. Journal of Neuropsychiatry and Clinical Neurosciences, 13(2), 229-242. https://doi. org/10.1176/appi.neuropsych.13.2.229. 
Tsuruta, R., Nakahara, T., Miyauchi, T., Kutsuna, S., Ogino, Y., Yamamoto, T., et al. (2010). Prevalence and associated factors for delirium in critically ill patients at a Japanese intensive care unit. General Hospital Psychiatry, 32(6), 607-611. https://doi.org/10.1016/j.genhosppsych.2010.09.001.

Vahedian-Azimi, A., Ebadi, A., Ahmadi, F., \& Saadat, S. (2015). Delirium in prolonged hospitalized patients in the intensive care unit. Trauma Monthly, 20(2), e17874. https://doi.org/10.5812/traum amon. 17874.

Van Rompaey, B., Schuurmans, M. J., Shortridge-Baggett, L. M., Truijen, S., \& Bossaert, L. (2008). Risk factors for intensive care delirium: A systematic review. Intensive \& Critical Care Nursing, 24(2), 98-107. https://doi.org/10.1016/j.iccn.2007.08.005.

von Elm, E., Altman, D. G., Egger, M., Pocock, S. J., Gøtzsche, P. C., \& Vandenbroucke, J. P. (2007). The strengthening the reporting of observational studies in epidemiology (STROBE) statement: Guidelines for reporting observational studies. Annals of Internal Medicine, 147(8), 573-577. https ://doi.org/10.7326/0003-4819-147-8-200710160-00010.

Wall, R. J., Engelberg, R. A., Gries, C. A., Galvan, B., \& Curtis, J. R. (2007). Spiritual care of families in the intensive care unit. Critical Care Medicine, 35(4), 1084-1090. https://doi.org/10.1097/01. CCM.0000259382.36414.06.

Whitehead, C., Finucane, P., Henschke, P., Nicklason, F., \& Nair, B. (1997). Use of patient restraints in four Australian teaching hospitals. Journal of Quality in Clinical Practice, 17(3), 131-136.

Williams, T. A., Ho, K. M., Dobb, G. J., Finn, J. C., Knuiman, M., \& Webb, S. A. R. (2010). Effect of length of stay in intensive care unit on hospital and long-term mortality of critically ill adult patients. British Journal of Anaesthesia, 104(4), 459-464. https://doi.org/10.1093/bja/aeq025.

World Health Organization. (1998). WHOQOL and spirituality, religiousness and personal beliefs (SRPB). Geneva: World Health Organization. https://apps.who.int/iris/handle/10665/70897. Accessed 9 Jan 2019.

Yadak, M., Ansari, K. A., Qutub, H., Al-Otaibi, H., Al-Omar, O., Al-Onizi, N., et al. (2019). The effect of listening to Holy Quran recitation on weaning patients receiving mechanical ventilation in the intensive care unit: A pilot study. Journal of Religion and Health, 58(1), 64-73. https://doi. org/10.1007/s10943-017-0500-3.

Yamaguchi, T., Tsukioka, E., \& Kishi, Y. (2014). Outcomes after delirium in a japanese intensive care unit. General Hospital Psychiatry, 36(6), 634-636. https://doi.org/10.1016/j.genhosppsy ch.2014.09.006.

Publisher's Note Springer Nature remains neutral with regard to jurisdictional claims in published maps and institutional affiliations.

\section{Affiliations}

Behrooz Farzanegan ${ }^{1}$ ( ) Takwa H.M. Elkhatib ${ }^{2}$. Alaa E. Elgazzar ${ }^{3}$. Keivan G. Moghaddam ${ }^{4} \cdot$ Mohammad Torkaman $^{5} \cdot$ Mohammadreza Zarkesh $^{6}$. Reza Goharani ${ }^{7}$. Farshid R. Bashar ${ }^{8} \cdot$ Mohammadreza Hajiesmaeili $^{7}$. Seyedpouzhia Shojaei ${ }^{7}$. Seyed J. Madani ${ }^{9}$. Amir Vahedian-Azimi ${ }^{10}$. Sevak Hatamian ${ }^{11}$. Seyed M.M. Mosavinasab ${ }^{12}$. Masoum Khoshfetrat ${ }^{13}$. Ali K. Khatir ${ }^{14}$. Andrew C. Miller ${ }^{15}$. for the MORZAK Collaborative

1 Tracheal Diseases Research Center, Anesthesia and Critical Care Department, Masih Daneshvari Hospital, Shahid Beheshti University of Medical Sciences, Tehran, Iran

2 Department of Neurology, Zagazig University, Sharkia, Egypt

3 Department of Chest Diseases, Zagazig University, Sharkia, Egypt

4 Department of Internal Medicine, Shariati Hospital, Tehran University of Medical Sciences, Tehran, Iran 
5 Department of Pediatrics, School of Medicine, Baqiyatallah University of Medical Sciences, Tehran, Iran

6 Department of Pediatrics, School of Medicine, Tehran University of Medical Sciences, Tehran, Iran

7 Anesthesiology Research Center, Anesthesia and Critical Care Department, Loghman Hakim Hospital, Shahid Beheshti University of Medical Sciences, Tehran, Iran

8 Anesthesia and Critical Care Department, Hamadan University of Medical Sciences, Hamadan, Iran

9 Trauma Research Center, Medicine Faculty, Baqiyatallah University of Medical Sciences, Tehran, Iran

10 Trauma Research Center, Nursing Faculty, Baqiyatallah University of Medical Sciences, Tehran, Iran

11 Anesthesia and Critical Care Department, Alborz University of Medical Sciences, Karaj, Iran

12 Anesthesiology Research Center, Anesthesia Care Department, Modares Hospital, Shahid Beheshti University of Medical Sciences, Tehran, Iran

13 Anesthesiology Research Center, Anesthesia and Critical Care Department, Khatam-o-anbia Hospital, Zahedan University of Medical Sciences, Zahedan, Iran

14 Anesthesiology Research Center, Anesthesia and Critical Care Department, Taleghani Hospital, Shahid Beheshti University of Medical Sciences, Tehran, Iran

15 Department of Emergency Medicine, Vidant Medical Center, East Carolina University Brody School of Medicine, 600 Moye Blvd, Greenville, NC 27834, USA 